\title{
Estudo de caso da aplicação de microgeração energética por painéis fotovoltaicos para utilização em bombas de captação de água
}

O presente trabalho tem como busca desenvolver tecnicamente analises mais próximas do real tendo como principal enfoque o método refinado de análise de aproveitamento energético por meio de painéis fotovoltaicos para bombeamento de água, analisando a eficiência dos projetos estudados bem como a sua viabilidade econômica mostrada através de um payback para obtenção de resposta de qual sistema melhor atende as necessidades de uma determinada população. Para completo entendimento do desenvolvimento a ser dado ao tema se faz necessário estabelecer e definir dois grupos de fonte de energia: as renováveis e as não renováveis, exemplificando cada uma delas. Vale ressaltar que a vantagem do uso de energia a partir de fontes renováveis não se restringe apenas ao âmbito econômico e político, focaliza também com a mesma relevância, a preservação da natureza em oposição ao impacto ambiental causado pelos combustíveis fósseis e ao consumo da água potável pela população. O método de análise é uma pesquisa exploratória, uma vez que utiliza conhecimento de um estudo de caso para resolução combustíveis fósseis e ao consumo da água potável pela população. O método de análise é uma pesquisa exploratória, uma vez que utiliza conhecimento de um estudo de caso para resolução de problemas. Foi analisado um sistema fotovoltaico para bombeamento de água: Sistema de Bombeamento Fotovoltaico aplicado em pequenas comunidades. Partindo da viabilidade conômica o sistema provou ser econômico e com retorno financeiro rápido, além da fácil utizaçásica do ser humano, colocando em evidência dados que comprovam a crise hídrica em locais de difícil acesso à energia elétrica e ao próprio recurso natural mais precioso: Agua.

Palavras-chave: Água; Energia; Energia Solar; Sustentabilidade; Engenharia.

\section{Case study of the application of energy microgeneration by photovoltpanels for use in water capture pumps}

\begin{abstract}
The present work seeks to develop technically closer analyzes of the real, having as main focus the refined method of analysis of energy utilization by means of photovoltaic panels for wate pumping, analyzing the efficiency of the studied projects as well as their economic feasibility shown through a payback to get response of which system best meets the needs of a given population. For a complete understanding of the development to be given to the theme, it is necessary to establish and define two groups of energy sources: renewable and non-renewable, per it is worth mentioning that the advan the same relevance, the presen analysis is an exploratory research, since it uses know applied in small communities. Starting from economic viability, the first system is what proved to be more economical and with a faster financial return, besides the easy use and installation of the system. The purpose of the present study was to raise awareness and propagate the importance of the availability of a water resource that is a basic human need, highlighting data that prove the water crisis in places that are difficult to access to electricity and natural resources most precious: Water.
\end{abstract}

Keywords: Water; Energy; Solar Energy; Sustainability; Engineering.

Topic: Engenharia Civil

Reviewed anonymously in the process of blind peer
Received: 09/11/2019

Approved: 29/12/2019
Jessica Santiago dos Santos (iD

Universidade da Amazônia, Brasil

http://lattes.cnpq.br/2606205332466179

http://orcid.org/0000-0002-1673-8080

eng.jessicaprof@gmail.com

Osmar Fonseca Garcia

Centro Universitário de Maringá, Brasil

http://lattes.cnpq.br/5798789968185112

http://orcid.org/0000-0002-4111-4253

osmarfgarcia@gmail.com

Saulo Hercules Silva da Silva

Universidade da Amazônia, Brasil

http://lattes.cnpq.br/7047517025124753

http://orcid.org/0000-0002-0920-8831

saullo.shs@gmail.com
Laura Mendonça Ponte Souza ito

Universidade Federal do Pará, Brasil

http://lattes.cnpq.br/4077195565302970

http://orcid.org/0000-0002-5262-9703

lauramps@outlook.com
Referencing this:

SANTOS, J. S.; GARCIA, O. F.; SILVA, S. H. S.; SOUZA, L. M. P.. Estudo de caso da aplicação de microgeração energética por painéis fotovoltaicos para utilização em bombas de captação de água. Technology Science, v.2, n.1, p.43-52, 2020. DOI:

http://doi.org/10.6008/CBPC2674-6425.2020.001.0008

DOI: 10.6008/CBPC2674-6425.2020.001.0008 


\section{INTRODUÇÃO}

Hodiernamente, o Brasil e o mundo buscam alternativas para tornar o planeta sustentável. Assim, uma das maneiras para que as gerações futuras tenham melhor qualidade de vida é conhecer e aplicar práticas de desenvolvimento ambiental. Não obstante, observa-se o crescimento acentuado da utilização de eletrodomésticos e utensílios em geral nas residências e indústrias, tornando necessário mais energia. Consequentemente há a uma diminuição de matérias primas primordiais, como petróleo e carvão vegetal. Assim, surgem no cenário as fontes renováveis, isto é, nascentes de energia que existem no ambiente em que vivemos: o sol, o ar, a água, etc.. Sendo assim, uma opção de grande valia para a sociedade moderna são essas fontes alternativas.

Nesse sentido, uma das metas do século XXI de grandes países é substituir, aos poucos, as fontes tradicionais, por tornarem-se escassas e caras, por fontes naturais, que são abastadas e inesgotáveis para a geração de energia. Portanto, ultimamente, vem sendo estudada e aplicada cada vez mais novas fontes de energia. Para um completo entendimento do desenvolvimento a ser dado ao tema, faz-se necessário estabelecer e definir dois grupos de fonte de energia: as renováveis e as não renováveis.

“As energias renováveis são aquelas originárias de ciclos naturais de conversão da radiação solar, fonte primária de quase toda energia disponível na Terra. Por isso, são praticamente inesgotáveis e não alteram o balanço térmico do Planeta" (PACHECO, 2006). Como por exemplo: a energia hidrelétrica, solar, eólica, do mar e geotérmica. Por sua vez, a energia não renovável é a aquela após sua transformação, a matéria-prima utilizada já não se aplica mais ao seu uso. Por exemplo, tem-se o petróleo, o carvão e o gás.

Destarte, vale ressaltar que a vantagem do uso de energia a partir de fontes renováveis não se restringe apenas ao âmbito econômico e político. Focaliza também com a mesma relevância, a preservação da natureza em oposição ao impacto ambiental causado pelos combustíveis fósseis e ao consumo da água potável pela população.

Concernente à água, aborda-se inicialmente, que está ocupa quase três quartos de toda a superfície da Terra, sendo um dos principais recursos que propiciam a vida. "Aproximadamente 97,13\% de toda água mundial é salgada e apenas $2,87 \%$ é doce, onde $78,05 \%$ se concentram em geleiras; $21,32 \%$ em subsolos e $0,63 \%$ na atmosfera, rios e lagos" (BENEDETTI, 2013).

Nessa perspectiva, verifica-se que a utilização desse recurso pelo homem tem a finalidade de prover suas necessidades pessoais, da produção industrial e agrícola. Entretanto, quando o uso da água é realizado de maneira incorreta, incide em alterações na qualidade de vida dos indivíduos e dos recursos hídricos. Além disso, a água potável para milhares de pessoas, ainda é de difícil acesso, sobretudo nos países em desenvolvimento.

O Brasil é composto por 5.565 municípios e com mais de 21 cidades metropolitanas (IBGE, 2010). Nessa visão, a água acaba sendo uma grande preocupação, devido ao intenso e rápido aumento do consumo desse recurso. Em diversas regiões brasileiras, existem situações de escassez, que acontecem em razão de condições naturais. Todavia, também pelo mau uso da água, da contaminação dos recursos hídricos, 
poluição, crescimento demográfico, entre outros fatores. "Mesmo diante de grandes inovações tecnológicas e acontecimentos ao longo dos tempos, ainda existe no Brasil, pessoas que moram em áreas urbanas e que não têm acesso a água potável" (CARMO et al., 2013).

Segundo o levantamento inédito da ANEEL - Agência Nacional de Energia Elétrica, o Brasil ainda possui 1 milhão de residências sem luz, sendo a maioria, na região Norte e Nordeste, principalmente em comunidades rurais e/ou isoladas. A falta de energia elétrica incide diretamente no abastecimento de água de boa parte dessas comunidades que dependem de bombas elétricas e muitas vezes do uso do uso de sistemas a diesel.

No Brasil, $72,2 \%$ da população rural ainda acessa água apenas por meio de poços, cacimbas, açudes e barreiros (IBGE, 2010). Acesso esse muitas vezes precário e com grande potencial para ocasionar o surgimento de doenças. Estima-se que de $2 \%$ a $3 \%$ do consumo de energia do mundo ocorram em sistemas de bombeamento de água, responsável por cerca de 90\% a 95\% do total dos gastos com energia elétrica.

Sendo assim, o interesse pelo tema proposto neste projeto parte da consideração de toda a problemática envolvendo o acesso à água potável e a sustentabilidade pelo uso da energia renovável. A proposta deste estudo é questionar a aplicação de microgeração energética e como pode refletir e contribuir na otimização de um sistema de bombeamento com eficácia e qualidade, gerando economia e sustentabilidade em contribuição para a sociedade de forma geral.

\section{METODOLOGIA}

O presente trabalho é uma pesquisa exploratória, uma vez que utiliza o conhecimento de um estudo de caso para resolução de problemas. Detectou-se também a necessidade da pesquisa bibliográfica no momento em que se fez uso de materiais já elaborados: livros, artigos científicos, revistas, documentos eletrônicos e enciclopédias. Na busca e alocação de conhecimento sobre o uso de energia renovável no projeto de implantação de bombeamento predial, correlacionando tal conhecimento com abordagens já trabalhadas por outros autores. Neste trabalho será analisado um sistema fotovoltaico para bombeamento de água: Sistema de Bombeamento Fotovoltaico aplicado em pequenas comunidades.

A abordagem do tratamento da coleta de dados será quantitativa, pois busca fonte direta para reconhecimento de informações, interpretação de fenômenos e atribuição de significados. Obtém a opinião de entrevistados sobre o tema do trabalho, como por exemplo, questionamentos acerca da melhoria de vida com a utilização da energia solar fotovoltaica. Apresentaremos um texto da análise das questões. Para a execução deste trabalho foi necessário a definição de três etapas: $1^{\circ}$ Etapa: definição e caracterização da área de estudo; 2ํㅡtapa: roteirização do processo de instalação; $3^{\circ}$ Etapa: Análise de Resultados.

Sistema de bombeamento fotovoltaico aplicado em pequena comunidade sem armazenamento de energia

\section{Área de estudo}

A cidade de Belém é rodeada de comunidades e ilhas, das quais, a maioria apresenta dificuldades de 
acesso à água para o consumo de seus moradores. A necessidade de tornar acessível a água potável para esses locais leva a buscar alternativas, como por exemplo, o Bombeamento de água por painéis fotovoltaicos. As empresas que trabalham com energia renovável vêm se aperfeiçoando cada vez mais nesses métodos optativos e tecnológicos, que buscam qualidade de vida associado ao baixo custo para esses locais.

Foi realizada uma ação social no dia 09/12/2017, dentro de uma comunidade no distrito de Icoaraci, cidade de Belém, estado do Pará (Figura 1) onde foi instalado pelos autores um sistema de bombeamento solar localizada ás margens do rio Maguari que sofria com a necessidade de água, para abastecer as 17 famílias residentes na comunidade receberam a instalação de um sistema de bombeamento solar que passou a fornecer 5.000 litros de água por dia para as famílias.

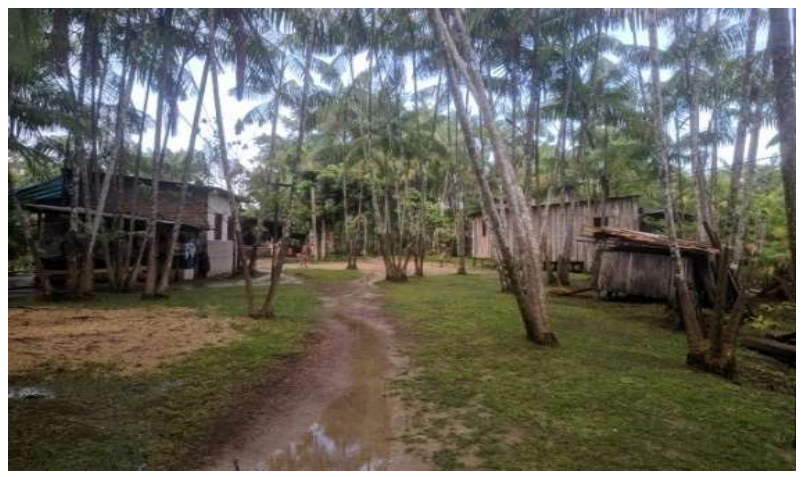

Figura 1: Comunidade de Piraíba.

\section{Roteirização do processo de instalação}

Para a instalação desse sistema foi composto um arranjo fotovoltaico, uma bomba SHURflo e cabo solar, conforme roteiro da figura 2 .

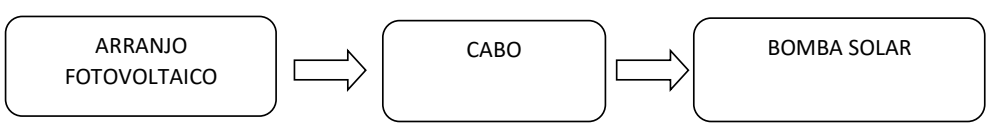

Figura 2: Sistema fotovoltaico proposto.

O Painel Solar Fotovoltaico de $150 \mathrm{Wp}$ da Risen (Figura 3) usado para o sistema em questão tem alta eficiência em módulos multicristalino, garantindo desempenho confiável ao longo do tempo. Os Painéis Fotovoltaicos da Risen Solar contam com tecnologia de nível mundial, passando nos testes de qualidade mais agressivos.

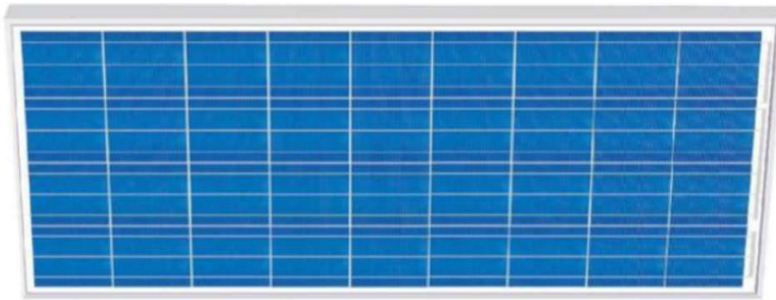

Figura 3: Módulo Fotovoltaico de $150 \mathrm{Wp}$ da Risen. Especificações Técnicas do Painel de 150Wp de Energia Solar Máxima Potência $(\mathrm{Pm})$ : Tolerância:

150 Watts $\pm 3 \%$

Voltagem de Máxima Potência $(\mathrm{Vm})$ : Corrente de Máxima Potência (Im):

18,3 Volts 8,20 Amps Voltagem de Circuito Aberto (Voc):
22,3 Volts 
Corrente de Curto-Circuito (Isc):

*Condição padrão de teste STC/CPT: Irradiação de $1.000 \mathrm{~W} / \mathrm{m}^{2}$, Espectro de Massa de $\operatorname{Ar} 1.5$ e Temperatura de Célula de $25^{\circ} \mathrm{C}$

Dimensões do painel:

Código IP da caixa

de junção:

Número de células

$$
\text { E tipo: }
$$

Peso do módulo:

Vidro, tipo e espessura:

\section{Especificações Mecânicas do Painel Solar:}

$(1480 \times 680 \times 35) \mathrm{mm}$

IP 67, 3 diodos

36, Silício Policristalino

$$
11,0 \mathrm{~kg}
$$

Vidro Solar de Alta Transparência, liga de alumínio anodizado, vidro temperado 3,2mm

Foi usado dois cabos solar de $4 \mathrm{~mm}$ da marca Conduspar (Figura 4), cabos indicados para ligações de painéis fotovoltaicos, proporcionando confiabilidade nos sistemas de geração de energia solar.

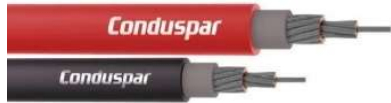

Figura 4: Cabo Solar.

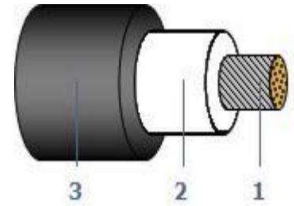

Figura 5: Composição do Cabo Solar.

1. Parte interna fio de Cobre eletrolítico estanhado, encordoamento flexível classe 5 - Conforme NBR NM 280; 2 . Isolação: Composto termofixopoliolefínico não halogenado; 3. Isolação: Composta termofixopoliolefínico não halogenado, retardante de chamas, resistente à radiação UV e intempéries.

A composição básica do Cabo Solar da Conduspar preto $4 \mathrm{~mm}^{2}$ é a descrita abaixo (Figura 5), separada por 3 camadas. Com a utilização de uma Bomba Solar Shurflo 2088 12V (Figura 6), utilizada nesse sistema se torna dispensável o uso de qualquer outro componente para o funcionamento do sistema, como por exemplo, inversores e baterias, porém, tem-se exceções.

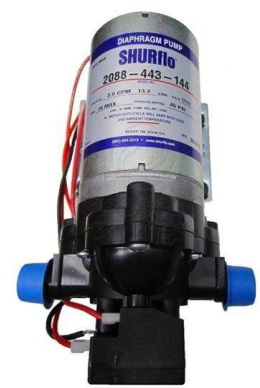

Figura 6: Bomba Solar Shurflo.

Conforme a descrição do seu fabricante, a Shurflo 2088 é capaz de fornecer alta vazão com pressão mediana, é uma bomba de superfície flutuante (não serve para poço artesiano) ideal para aplicações residenciais ou rurais. Consome baixa amperagem e é capaz de recalcar até $35 \mathrm{~m}$. É uma bomba com construção leve e altamente resistente à corrosão e ferrugem com fácil reparo no local. De acordo com o dimensionamento realizado, a quantidade de água necessária para a comunidade em questão é $2.750 \mathrm{~L} / \mathrm{dia}$. Considerando o índice solarimétrico médio do Pará: $5 \mathrm{Kwh} / \mathrm{m}^{2}$ ( 5 horas de sol pleno) precisa-se achar primeiro a vazão necessária: Quantidade de água necessária para a comunidade $=2.750 \mathrm{~L} / \mathrm{dia}$ 


$$
\begin{aligned}
& \text { Índice Solarimétrico }=5 \mathrm{Kwh} / \mathrm{m}^{2} \\
& \qquad \begin{array}{c}
V=2750 \div 5 \\
V=550 \mathrm{~L} / \mathrm{h}
\end{array}
\end{aligned}
$$

Agora, acha-se a pressão necessária AMT = pressão (altura manométrica) AS = Altura de sucção $\mathrm{AR}=$ Altura de recalque $\mathrm{PC}=$ Fator de perda de carga $\mathrm{FS}=$ Fator de segurança Fórmula $=\mathrm{AMT}=(\mathrm{AS}+\mathrm{AR}+\mathrm{PC})+\mathrm{FS}$

Antes, é necessário encontrar o fator de perda de carga (PC) e para isso basta multiplicar a distância total da tubulação pelo fator de perda que normalmente é $8,5 \%$. A altura de sucção é de $6 \mathrm{~m}$, de recalque é $7 \mathrm{~m}$ e o fator de segurança $5 \%$.

$$
A M T=(A S+A R+(17 \times 0,085)) \times 5 \%
$$

Substituindo, tem-se:

$$
\begin{gathered}
A M T=(6+7+(17 * 0.085) \times 5 \% \\
A M T=(13+1,5) \times 5 \% \\
A M T=15,23 \text { M.C.A } \cong 16 M C A
\end{gathered}
$$

A bomba necessária deve vir com pressão de 16 mca e vazão de 550L/h. Verificando o datasheet da bomba da Figura 7.

\begin{tabular}{|ccccc|}
\hline $\begin{array}{c}\text { PRESSÄO } \\
\text { (PSI) }\end{array}$ & $\begin{array}{c}\text { VAZÄO } \\
\text { (LPM) }\end{array}$ & $\begin{array}{c}\text { RPM } \\
\text { MIN/MAX }\end{array}$ & $\begin{array}{c}\text { CORRENTE } \\
\text { (AMPS) }\end{array}$ & $\begin{array}{c}\text { VOLTAGEM } \\
\text { (VOLTS) }\end{array}$ \\
ABERTO & 13.2 & $2160 / 2210$ & 5.3 & $12 \mathrm{VCC}$ \\
10 & 10.7 & $2130 / 2180$ & 5.8 & $12 \mathrm{VCC}$ \\
20 & 9.7 & $2050 / 2110$ & 7.0 & $12 \mathrm{VCC}$ \\
30 & 8.7 & $2015 / 2030$ & 8.0 & $12 \mathrm{VCC}$ \\
40 & 7.6 & $1960 / 1975$ & 9.1 & $12 \mathrm{VCC}$ \\
50 & 6.6 & $1915 / 1930$ & 9.9 & $12 \mathrm{VCC}$ \\
\hline
\end{tabular}

Figura 7: Datasheet da bomba.

\begin{tabular}{|ccccc|}
\hline $\begin{array}{c}\text { PRESSĀO } \\
\text { (PSI) }\end{array}$ & $\begin{array}{c}\text { VAZŻ̈O } \\
\text { (LPM) }\end{array}$ & $\begin{array}{c}\text { RPM } \\
\text { MINMMAX }\end{array}$ & $\begin{array}{c}\text { CORRENTE } \\
\text { (AMPS) }\end{array}$ & $\begin{array}{c}\text { VOLTAGEM } \\
\text { (VOLTS) }\end{array}$ \\
\hline 10 & 10.7 & $2130 / 2180$ & 5.8 & $12 \mathrm{VCC}$ \\
\hline 20 & 2.7 & $2050 / 2110$ & 7.0 & $12 \mathrm{VCC}$ \\
30 & 2.7 & 201512030 & 2.0 & $12 \mathrm{VCC}$ \\
\hline 40 & 7.6 & $1960 / 1975$ & 2.1 & $12 \mathrm{VCC}$ \\
50 & 6.6 & $1915 / 1930$ & 2.9 & $12 \mathrm{VCC}$ \\
\hline
\end{tabular}

Figura 8: Datasheet da bomba (com destaque).

Percebe-se que a unidade de pressão da bomba ta em PSI, tem-se que converter MCA para PSI:

$$
1 \mathrm{MCA}=1,43 \text { PSI logo, } 16 \times 1,43=22,88 \text { PSI }
$$

De acordo com a tabela acima (Figura 8), a pressão fica entre 20 e 30 PSI, dessa forma foi admitido 9,2L/min em uma corrente de 8A e 12V. Verificando o datasheet do painel da Risen RSM36-6-150P de 150W (Figura 9).

\section{Electrical Characteristics}

\begin{tabular}{ccccccc}
\hline Model & $\mathrm{Pm}(\mathrm{Wp})$ & Tolerance & $\mathrm{Vm}(\mathrm{V})$ & $\mathrm{Im}(\mathbf{A})$ & $\mathrm{Voc}(\mathrm{V})$ & $\mathrm{Isc}(\mathbf{A})$ \\
\hline RSM36-6-130P & $130 \mathrm{~W}$ & $+-3 \%$ & 17.6 & 7.41 & 21.8 & 8.03 \\
\hline RSM36-6-140P & $140 \mathrm{~W}$ & $+-3 \%$ & 18.1 & 7.72 & 22.1 & 8.32 \\
\hline RSM36-6-150P & $150 \mathrm{~W}$ & $+-3 \%$ & 18.3 & 8.20 & 22.3 & 8.81 \\
\hline RSM36-6-160P & $160 \mathrm{~W}$ & $+-3 \%$ & 18.6 & 8.60 & 22.5 & 8.88 \\
\hline
\end{tabular}

Valued al STC (AM 1.5, 1000W/m², 25C)

Figura 9: datasheet do painel da Risen RSM36-6-150P de 150W. 
Confirmando assim, que o Painel atende a necessidade: 9,2L/m $\times 60$ minutos $=552$ litros/horas nessa pressão. Durante o processo de instalação foi registrado a instalação da Bomba Shurflo (Figura 10); o momento em que o módulo fotovoltaico está sendo erguido para uma estrutura de madeira(Figura 11) e a instalação e ligação dos cabos Conduspar entre a bomba e o módulo fotovoltaico (Figura 12).

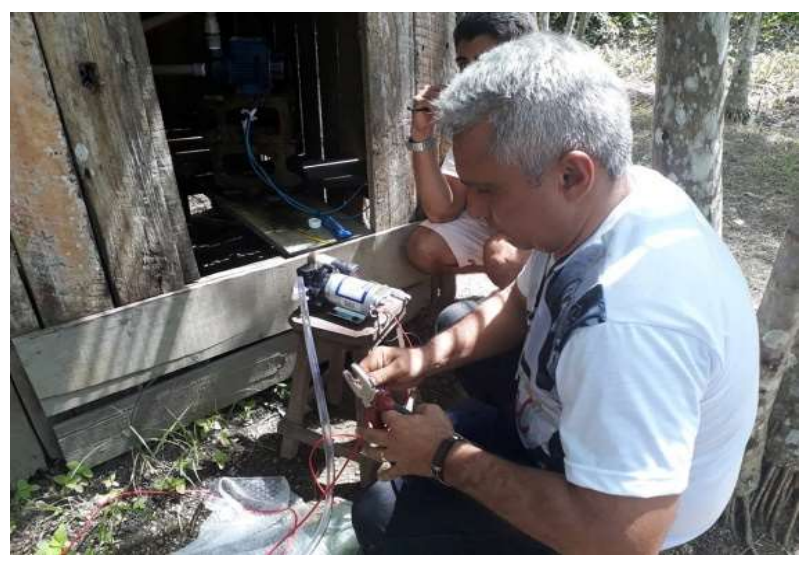

Figura 10: Bomba Solar Shurflo sendo instalada.

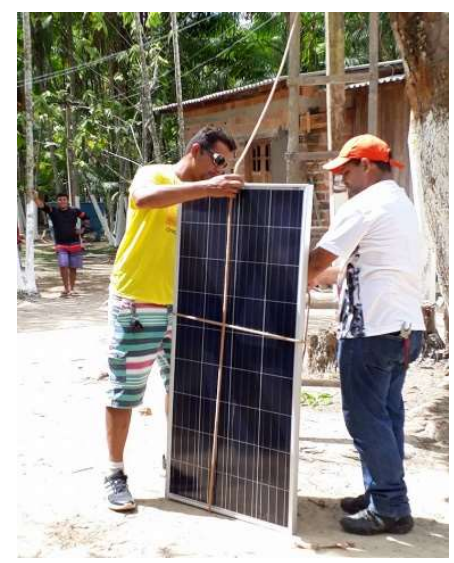

Figura 11: Fotovoltaico de 150Wp da Risen sendo instalada na comunidade.

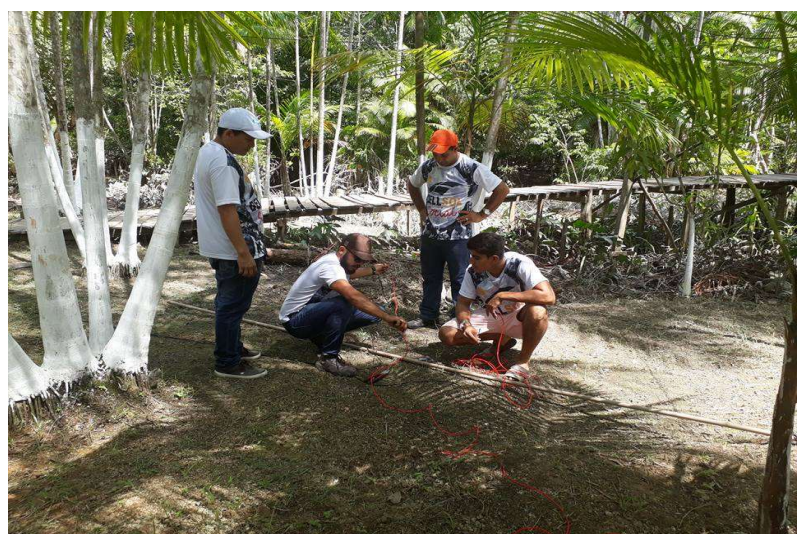

Figura 12: Cabo solar utilizado no sistema.

\section{RESULTADOS E DISCUSSÃO}

\section{Consumo de Água}

O dimensionamento do projeto estipula que a quantidade de água necessária para a comunidade é de 2.750 litros/dia, e a média considerando trinta dias corridos é de 82.500 litros/mês. O cálculo do consumo de água se baseia na tarifa da Companhia de Saneamento do Pará (COSANPA, 2018), onde diz que o consumo de até $10 \mathrm{~m}^{3}$ que equivale a 10 mil litros de água é um valor fixo de $\mathrm{R} \$ 2,49$ e a cada $10 \mathrm{~m}^{3}$ e mais esse valor aumenta. Considerando a tabela tarifária da COSANPA, na categoria Residência com uma faixa de consumo acima de $50 \mathrm{~m}^{3}$, tem-se um valor fixo de $\mathrm{R} \$ 9,68$ cada $\mathrm{m}^{3}$ consumido. Diante disto, tendo um consumo de 82.500 litros/mês de água tem-se um custo mensal de $\mathrm{R} \$ \mathbf{7 9 8 , 6 0}$ mensais a ser pago pela comunidade.

\section{Consumo de energia}

Quando se faz a instalação de um sistema de água, devem ser consideradas diversas variáveis no momento da escolha. Além disso, os custos para executar esse sistema deve ser levado em consideração, e 
um deles é o consumo de energia.

Para calcular o consumo médio de energia ( $\mathrm{kWh}$ ) de uma bomba d'água, de acordo com o hábito de uso, deve-se procurar a potência do aparelho no manual do fabricante. Em seguida, faz-se o cálculo da seguinte forma: Potência do equipamento (W) x № de horas utilizadas $\mathbf{x}$ № de dias de uso ao mês 1.000. Logo abaixo, na Tabela 1, temos uma estimativa de consumo médio de bombas d'água, em uso hipotético.

Tabela 1: Estimativa de consumo de bombas d'água.

\begin{tabular}{|c|c|c|c|c|}
\hline MODELOS DE BOMBAS & $\begin{array}{c}\text { Potência Média } \\
\text { Watts }\end{array}$ & $\begin{array}{c}\text { Dias Estimados } \\
\text { Uso/Mês }\end{array}$ & $\begin{array}{c}\text { Média } \\
\text { Utilização/Dia }\end{array}$ & $\begin{array}{c}\text { Consumo Médio Mensal } \\
\text { (kwh) }\end{array}$ \\
\hline BOMBA D' ÁGUA 1/4 CV & 335 & 30 & $1 \mathrm{H}$ & 10,05 \\
\hline BOMBA D' ÁGUA 1/2 CV & 613 & 30 & $1 \mathrm{H}$ & 18,39 \\
\hline BOMBA D' ÁGUA 3/4 CV & 849 & 30 & $1 \mathrm{H}$ & 25,47 \\
\hline BOMBA D' ÁGUA 1 CV & 1051 & 30 & $1 \mathrm{H}$ & 31,53 \\
\hline
\end{tabular}

Se for utilizado como modelo a Bomba D'Água de 1CV com consumo médio mensal de 31,53Kwh e de acordo com a Resolução Homologatória Aneel No 2.433/2018 a tarifa residencial convencional (R\$/kWh) está R\$0,67098 por kWh.

$$
31,53 \mathrm{kWh} \times 0,67098=\text { R\$21,15 por mês. }
$$

0 custo de energia do sistema de água utilizando uma bomba d'água será em média $R \$ 21,15$. Para o sistema de bombeamento solar apresentado, foi usado uma Bomba Solar Shurflo. E o caso em questão, não existe a necessidade de uso de energia elétrica para a realização do bombeamento, o que significa custo zero de energia.

\section{Investimento Inicial}

O investimento inicial feito nesse sistema será apresentado com os preços de seus respectivos equipamentos e o valor total investido (Tabela 2).

Tabela 2: Preços de equipamentos e Valor Total Investido.

\begin{tabular}{|l|l|l|}
\hline EQUIPAMENTO & QUANTIDADE & TOTAL \\
\hline BOMBA SOLAR SHURFLO 2088 & 1 & $\mathrm{R} \$ 1.400,00$ \\
\hline PAINEL SOLAR RISEN & 1 & $\mathrm{R} \$ 750,00$ \\
\hline CABO SOLAR CONDUSPAR & 2 & $\mathrm{R} \$ 250,00$ \\
\hline INSUMOS & - & $\mathrm{R} \$ 220,00$ \\
\hline VALOR TOTAL: & $\mathrm{R} \$ 2.620,00$ \\
\hline
\end{tabular}

\section{Payback}

A técnica do Payback é utilizada para examinar o período de tempo requerido para cobrir o custo de um investimento. Sendo assim, o investimento e a economia são de $R \$ 819,75$ a cada mês, no total de 4 meses.

$$
P B=\frac{\text { Investimento do Projeto }}{\text { Ganho a cada } \text { mês }}=\frac{2.620,00}{819,75} \cong 4 \text { meses }
$$

\section{CONCLUSÕES}

No Sistema de bombeamento fotovoltaico aplicado em pequena comunidade sem armazenamento 
de energia foi realizado uma visita um ano depois da instalação na Comunidade Piraíba, para verificação do funcionamento do Sistema e durante a visita realizamos a vistoria da Bomba no local onde fica armazenada (Figura 13 e 14) e do módulo fotovoltaico para saber suas condições (Figura 15).

De acordo, com os moradores da comunidade foi relatado que durante esse período de um ano que passou o Sistema de Bombeamento Solar mostrou eficiência, atendendo a necessidade da comunidade provando ser uma excelente alternativa para a crise de abastecimento de água em locais de difícil acesso. Segue nas Figuras 13, 14 e 15 fotos do Sistema um ano depois da instalação.

Através do relatório fotográfico é possível perceber que a comunidade carece de uma boa estrutura e por esse motivo não foi possível fotos melhores do sistema. O sistema se mostrou ser viável e econômico para pequenas comunidades, sem custos elevados, e dessa forma, tendo um retorno rápido do investimento que foi aplicado além do conceito de utilização de energia limpa. Vale ressaltar, que a implantação do sistema não resolve problemas de saneamento básico.

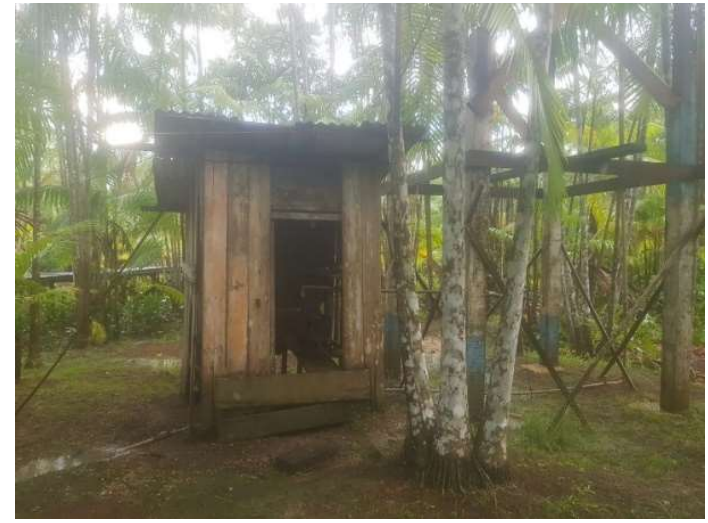

Figura 13: 'Casa' das Bombas.

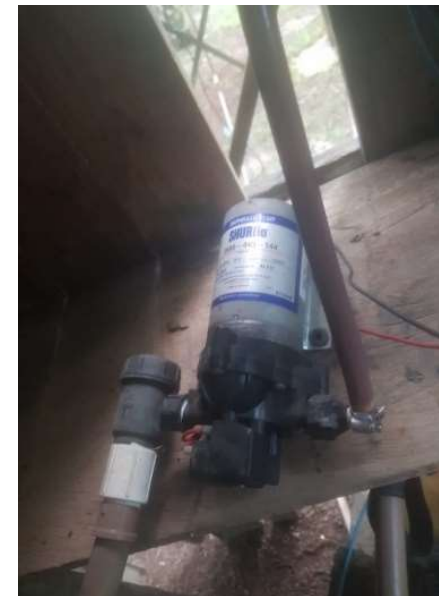

Figura 14: Bomba Solar.

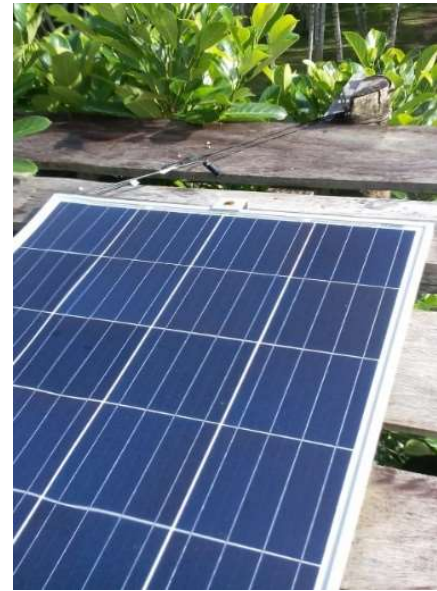

Figura 15: Módulo Fotovoltaico de $150 \mathrm{Wp}$ da Risen do sistema.

Apesar da instalação de bombeamento no local, a comunidade é bem grande e não tem uma estrutura adequada que atenda igualmente a todas as famílias, por esse motivo, famílias que moram do outro lado rio precisa se deslocar até a torneira mais próxima para poder fazer consumo da água, pois o local carece de tubulação adequada para toda a área.

O presente estudo teve como uma de suas finalidades conscientizar e propagar a importância da disponibilidade de um recurso hídrico que é necessidade básica do ser humano, colocando em evidência dados que comprovam a crise hídrica em locais de difícil acesso à energia elétrica e ao próprio recurso natural mais precioso: Água.

A propagação de novas fontes de energia, especialmente a energia solar fotovoltaica de destaca pela alta confiabilidade e flexibilidade de chegar a locais com acesso precário onde a rede convencional não chega. Destacando o bombeamento de água com aplicação da energia solar fotovoltaica foi feita uma descrição dos componentes que formam um sistema de bombeamento solar e suas especificações técnicas.

O sistema apresentado apresenta suas particularidades, tais como, o payback: um sistema simples 
com baixo custo de investimento com uso de uma bomba solar, portanto, não se faz necessário o uso de outros componentes no sistema, como por exemplo, um inversor. Dessa forma, o sistema se torna mais prático e didático para uso da comunidade.

É importante frisar que esse sistema se mostra muito mais vantajosos para residências ou comunidades utilizando bombas de uso fotovoltaico chamada de 'Bomba Solar' tanto pelo lado operacional como econômico. A aplicação desses sistemas para diversas comunidades carentes que temos na cidade de Belém sem acesso a água potável e/ou energia elétrica seria um engajamento social muito importante, além de aumentar o leque de pesquisas sobre o assunto, com a devida atenção governamental.

\section{REFERÊNCIAS}

BENEDETTI, E.. Água: fonte da vida: considerações. Veterinária Notícias, Uberlândia, v.18, n.1, p.1-5, 2013.

CARMO, R. L.; DAGNINO, R. S.; FEITOSA, F. F.; JOHANSEN, I. C.. População e consumo urbano de água no Brasil: interfaces e desafios. In: SIMPÓSIO BRASILEIRO DE RECURSOS HÍDRICOS. Anais. Porto Alegre, 2013.
COSANPA. Tabela tarifária a partir de 01/setembro/2018: Diretoria de mercado. Belém: COSANPA, 2018.

IBGE. Instituto Brasileiro de Geografia e Estatística. Censo demográfico. Rio de Janeiro: IBGE, 2010.

PACHECO, F.. Energias Renováveis: Breves Conceitos. Salvador: Conjuntura Econômica, 2006.

A CBPC - Companhia Brasileira de Produção Científica (CNPJ: 11.221.422/0001-03) detém os direitos materiais desta publicação. Os direitos referem-se à publicação do trabalho em qualquer parte do mundo, incluindo os direitos às renovações, expansões e disseminações da contribuição, bem como outros direitos subsidiários. Todos os trabalhos publicados eletronicamente poderão posteriormente ser publicados em coletâneas impressas sob coordenação da Sapientiae Publishing, da Companhia Brasileira de Produção Científica e seus parceiros autorizados. Os (as) autores (as) preservam os direitos autorais, mas não têm permissão para a publicação da contribuição em outro meio, impresso ou digital, em português ou em tradução. 